Armando T. Isla Jr., MD

Josefino G. Hernandez, MD

Department of Otorhinolaryngology College of Medicine - Philippine General Hospital University of the Philippines Manila
Correspondence: Armando T. Isla Jr., MD Department of Otorhinolaryngology Ward 10, Philippine General Hospital Taft Avenue, Ermita, Manila 1000 Philippines

Phone: (632) 5264360

Fax: (632) 5255444

Email: donisla.md@gmail.com

Reprints will not be available from the author.

\section{Retroverted Uncinate Process: An Anatomic Variation}

Considerable attention has been directed toward analysis of paranasal sinus anatomy through coronal plane computerized tomographic (CT) imaging in this age of functional endoscopic sinus surgery. Recently, it has become apparent that anatomic variations are also evident on $\mathrm{CT}$ analysis of patients. Subtle anatomic features can now be imaged through $\mathrm{CT}$, with a level of clarity previously not afforded by standard sinus radiographs. $^{1}$

The key to a successful endoscopic sinus surgery is the proper identification of landmarks, and intelligent decision-making should there be any doubts as to what structure lies ahead. The middle turbinate is the main landmark in the region and should be preserved if possible. Attention to the limits of the middle turbinate landmark is one of the keys to uncomplicated surgery. ${ }^{2}$ The presence of a retroverted uncinate process, wherein the uncinate process ( rather than the middle turbinate) is the first bone to encountered, can be misleading to the rhinologic surgeon and lead to inadequate surgery. Familiarity with anatomic variations such as the retroverted uncinate process should increase the safety and effectiveness of functional endoscopic sinus surgery.

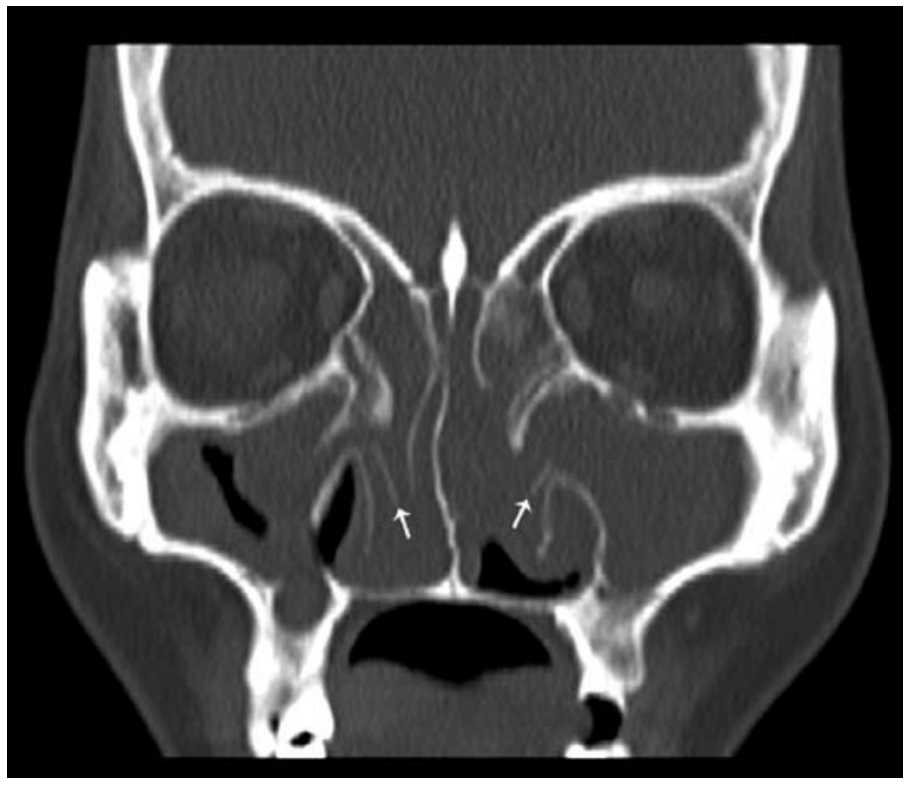

Figure. 1 Coronal CT image passing through the level of the osteomeatal complex in a patient with severe nasal polyposis. Arrows point to a retroverted uncinate process on both sides. Recognition of this anatomic abnormality is essential for the determination of surgical landmarks for endoscopic sinus surgery.

\section{REFERENCES}

1. Bolger WE. Paranasal sinus bony anatomic variations and mucosal abnormalities: CT analysis for endoscopic sinus surgery. Laryngoscope 101:56-64, 1991.

2. Freedman HM, Kern EB. Complications of intranasal ethmoidectomy: a review of 1000 consecutive operations. Laryngoscope 89:421-34, 1979. 